\title{
Aspects of Preservation of Architecture of the Early Modern Movement
}

\author{
HELEN G. WELLING \\ The Royal Academy of Fine Arts \\ Denmark
}

The following paper contains some of the main points of discussion in a research project about the preservation of architecture of the Modern Movement in preparation at the Royal Academy of Fine Arts, School of Architecture, Copenhagen. It discusses the relativity of historical values within the early Modern Movement. Various aspects on the case of preservation of architecture of the Modern Movement are explained. Different examples of restoration, reconstruction and new interventions are analysed and ordered in a series of methods. The conclusion is that the architecture of this epoch needs a new attitude especially towards the question of authenticity.

There is a tendency to view the Modern Movement as a closed subject. While the cultural crisis of the second half of the 60 's undoubtedly interrupted a relative continuity and introduced a long process of reaction. Great cultural cycles do not always conclude when a crisis occurs, however profound such a crisis may be. To put this in another way, theof that cycle gave rise to another, which continued as a further realisation of the former.

History is a process of evolution in which systems of cultural value only possess a relative truth. What appears absolutely true in one epoch is seen in the next to have been contingent. Thus each epoch erects its own self-justificatory system of values.

What makes the architecture of the Modern Movement worth maintaining and preserving? Perhaps the clean and timeless image, that appears on period photographs, interests us most. Saving or recuperating this initial appearance seems to bring us back to the heroic days of the movement. A number of recent restorations show how we do not allow Modernism to age, or at least we have problems in keeping a distance.

For more than a decade the preservation of architecture of the Modern Movement has been put into practice. The most frequent approach has been to preserve the work by restoring its original characteristics. However the heritage of Modern Architecture, which as a historical legacy has already completed its initial life cycle, may also be the object of transformation or extension. Consequently, it is also impor- tant to discuss the criteria for intervention which could be applied in each case to architecture of the Modern Movement.

The preservation and restoration of a building reflects often an idealisation of a certain 'style'. The concept of 'style' came first into being in the beginning of the 19 th Century. Gottfred Semper developed in the 1860 'ies a systematic ideology in his book "Der Stil", which is a typology about style. The central point in Sempers theory is his assertion that the artistic expression does not derive from form or proportions, but from style. For him, style was decoration, expressed through symbols.

The architects of the Modern Movement tried to escape any rules for a certain style. They researched all the necessary conditions around their ideas of a future life. Nonetheless there was also a hope that this search could result in a final 'style' (as for example expressed in the Dutch movement: "De Stijl").

Since the utopian dreams of the turn of the Century no longer can exist today, a strong belief in the qualities of our recent past is growing. This appreciation of the past results in mutual interchangeable concepts between the past, the present and the future. The prosperity of the Modern Movement leads to a direct reuse of their ideas in today's architecture.

The preservation and the reconstruction of the buildings of the Modern Movement show how both preservation and reconstruction are entangled in each other. A reconstruction of an original building, such as the l'Esprit Nouveau Pavilion of Le Corbusier, erected in Bologna in 1977, possibly looks more original than the Paris pavilion from the twenties. On the other hand are there no longer any limitations concerning the site and no longer difficulties concerning complicated ownerships. The reproductions can be built on the ideal site and be accessible for all potential target groups.

The importance of the reproductions that exist today demonstrate that the importance of the heritage of the Modern Movement is embedded far beyond the authenticity of site and the building materials. Instead there can be some sort of conceptual truth, an essence which is taken over and present or symbolised in a reproduction.

The reproduction might reflect, a concept, the memory of 
a moment in history or simply the space enclosed by an object and the way the light enters. One can speak about the surprising three-dimensional effects and the shock of seeing a former building realised. But there will always be the risk that the more we reconstruct and transfer, the more we loose contact with the innovative spirit we are so desperately looking seeking.

\section{SPECIAL CONDITIONS CONCERNING THE PRESERVATION OF THE BUILDINGS OF THE MODERN MOVEMENT}

There are special aspects in the case of preservation of architecture of the Modern Movement that are different from former architectural epochs. Architects of the Modern Movement did have another attitude towards the durability of a building. The building techniques were experimental with the risk that construction, materials and details weathered and behaved differently than in former architecture.

\section{The concept of authenticity in the Modern Movement}

Ideas about the preservation of the buildings of the Modern Movement should be related to the thoughts in the thirties of Walter Benjamin in his essay: The Work of Art in the Age of Mechanical Reproduction. Walter Benjamin distinguishes between three different periods: the traditional age, the age of collections, and the age of mechanical reproduction. Each age has its particular approach to authenticity in relation to works of art. In the early traditional context, art was initially seen in the service of cult, magic or religion, which was alive and changeable. Authenticity could then be conceived in the cultural dimension, and the 'aura' of the work of art in the quality of the traditional continuity, rather than in the historical uniqueness of a single object.

In the Renaissance art became a collector's item and was extensively copied, which resulted in a major emphasis on the artistic quality of the unique and original object.

According to Walter Benjamin, the concept of authenticity has become increasingly relevant particularly during the thirties. This was due to the fundamental change that occurred in the society world-wide at the same time. It was related to the introduction of new technologies and production methods, which allowed special attention to quantity and speed. In this way, art was produced for the enjoyment of large masses of people, at the same time, in a manner that would never have been conceivable earlier. The one-timeexisting condition and constancy of the original was replaced by ephemeral, repetitive and reproducible artefacts.

The same thoughts can be applied to architecture. The architecture of the Modern Movement serves the need for changing techniques of mass production, new materials and flexibility in function. The question of authenticity should be seen in a totally new manner, where the 'original' does not really exist in the same sense as in the past. For Walter Benjamin the adaptation of reality to the masses and the adaptation of the masses to reality was an act of unlimited extent within human thinking and perception.

The relation between the object and the viewer was further developed by Umberto Eco. Umberto Eco noted that art generally has two aspects: one is the creative process initiated by the artist, who defines the concept in view of its fruition and future enjoyment. The other refers to its enjoyment by a plurality of people representing different cultural and social characteristics, and the different requirements that may occur each time. As a result of these two aspects in important and lasting art, there will be a continuing dialogue between the work of art and the persons involved. Eco thus calls art Opera Aperta (an 'Open Work'). Many of today's artist have the same attitude towards their work.

The buildings of the Modern Movement contain an inherent temporality. Their building materials and constructionswere less durable than the building materials from other ages. Requirements concerning the authenticity are therefore more complicated. The following hierarchy concerning the question of authenticity could be applied:

1. Authenticity of the concept

2. Authenticity of appearance

3. Authenticity of building materials

However, defining the ethics of conservation and restoration in relation to architecture, or to the recent industrial heritage, requires further study. From the examples that are available today, there is a certain feeling that this needs cautious handling, just as other heritage sites, in order not to loose the essence and authenticity of the work.

\section{The transitoriness of the architecture of the Modern Movement}

In an attempt to surpass the cycle of styles, the Modern Movement had to be a future and permanent style, resulting in an architectural vocabulary of extreme volatility. The desire to express a constant actuality in the architecture of the buildings made them simultaneously uniquely vulnerable to deteriation.

It is paradoxical to prolong the existence of a building, whose original intention and physical structure was determined by its temporary functional program. Several of the buildings of the Modern Movement were purposedly planned with a short life span, both functionally and technically. How should these buildings be preserved? Is it possible to replace the original technology with a contemporary and more durable technology? Taken to its logical conclusion, the preservation of these buildings implies a direct misunderstanding of some of the most fundamental premises within the ideology of the Modern Movement.

The idea to exclude the worn-out buildings of the Modern Movement from any kind of preservation might be the right solution intellectually, but this attitude will finally result in the loss of an important cultural heritage. An architectural movement, with the characteristic of transitoriness, may not escape history. It represents a cultural image of its time and is as important to preserve as the most memorable and important buildings of other ages. 


\section{The changeability in the architecture of the Modern} Movement

To find a new compatible function for a building that no longer serves its original function is a solution that fits well into the ideas of the Modern Movement. Small alterations could consider the original idea: a building adapted to its function.

Many buildings of the Modern Movement have undergone alterations in their lifetime. The original architects have changed both the interiors and the exteriors. These building are planned with an inherent flexibility. The large spans allow the possibility of continuous changes. Walls can be easily removed and added to adapt to and serve changing functions.

\section{The idea of honesty in the appearance of material in} the architecture of the Modern Movement

The development of new building materials and construction methods and their introduction into the building practice has always been very influential - even if not exclusively - on the establishment of new formal and spatial concepts in architecture. In "Les 5 Points d'une Architecture Nouvelle" (1927), Le Corbusier and Pierre Jeanneret emphasised the formal and spatial potentials of a reinforced-concrete construction as already visualised schematically in the 'Domino-system'. Some buildings in Modernism truly express the new and advanced building technology of their time.

Other buildings, such as the Rietveld-Schröder house are technically rather conventional buildings, built of traditional load bearing brick walls, where the use of concrete is limited to small building parts. Some buildings express Modernity, but they are traditional in their materials. Other buildings are very modern in their use of technology and materials, but they do not express modernity in their formal appearance.

The architecture of the Modern Movement did not focus on matter itself. It placed more emphasis on characteristics as: opaqueness contra transparency, smooth and preferably precise surfaces, their reflection abilities and the perceptional ephemeral effects of the juxtaposition of complementary colours.

The choice of materials should emphasise the minimal need of creating the surrounding for a function. The materials should express the efficiency and economic advantages in the method of mass-production

Can a building constructed of mass-produced elements be authentic in its material? In case of preservation would be possible to reconstruct the process of mass-production of the thirties, when the need arises to replace a simple missing door handle?

\section{DIFFERENT EXAMPLES OF PRESERVATION WITHIN THE BUILDINGS OF THE MODERN MOVEMENT}

The examples of restoration and reconstruction in Europe (mostly in Holland) mentioned below show how different points of departure can result in different methods:

The complete restoration:

Many of the 'models' of the Modern Movement, such as the Rietveld-Schröder House, have undergone a complete restoration. It is often difficult to decide what is the most important image to save. The Rietveld-Schröder House has had several functions, and its interiors have been changed by the architects themselves. Many of these 'models' are now museums and contain important paradigms for the next generations.

\section{The complete reconstruction:}

Many of the buildings of the Modern Movement are demolished through weathering, insufficient building techniques or because they were originally planned as temporary structures. The most important examples of the Modern Movement were exhibition pavilions, most of which were first demolished and later reconstructed on the same site or elsewhere; some were even duplicated. Mies van der Rohes Pavilion in Barcelona was reconstructed at the same place after careful studies of the existing fragments of the foundation. The Pavilion of the Spanish Republic at the Paris Exhibition in 1937 was reconstructed in Barcelona and Le

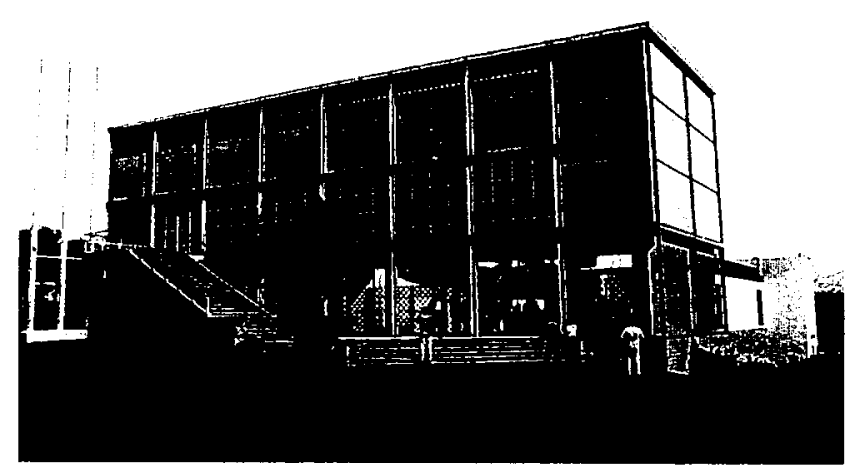

Fig. 1. J.L. Sert and L. Lacasa, the Spanish Pavilion from the Paris Exhibition of 1937, reconstructed in Barcelona

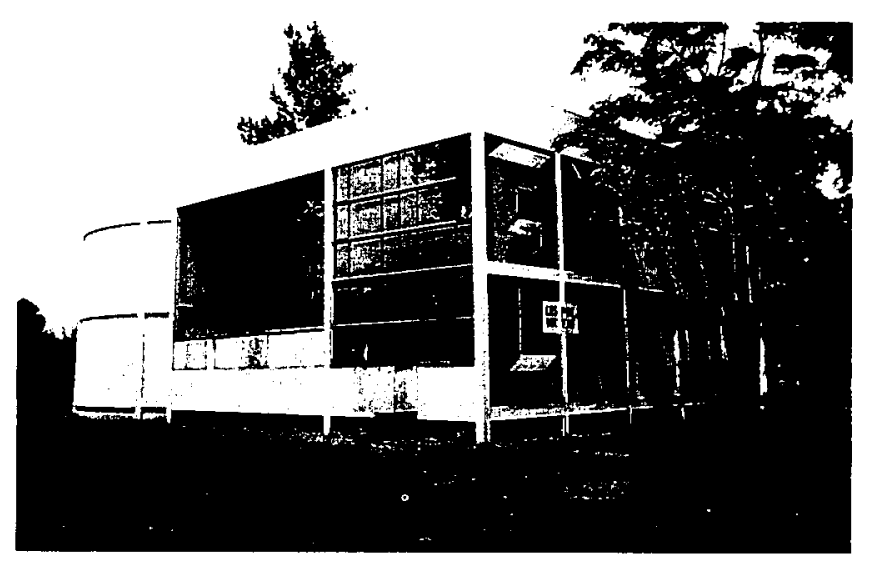

Fig. 2. The Pavilion L'Espirit Nouveau of Le Corbusier, originally built in Paris, 1925, reconstructed in Bologna in 1977 
Corbusier's Pavilion L'Esprit Nouveau has been reconstructed in Bologna. J.J.P. Oud's Mathenesse management shed was reconstructed at two sites in Holland. There is a need to create a possibility for experiencing these buildings three-dimensionally.

\section{Reconstruction of fragments:}

The reconstruction of parts of buildings can be done on facades or in interiors, like in Rotterdam where the facade of Oud's Café de Unie was reconstructed on an empty lot in the centre of the city. The building behind the facade is a contemporary building. The facade did not fit precisely in the empty lot and a narrow addition was designed to make it fit. Mondrian's studio in Paris from 1926 remained in a black and white photograph. By comparing the black, grey and white tones of the photo showing one of his still existing paintings with the real painting, it was possible to reconstruct the original colours of the room. Further studies uncovered also the original pentagonal plan of the studio. The Café Aubette in Strassbourg with interior designs by Theo van Doesburg has also been reconstructed. Many of these reconstructions are very useful for a better understanding of this architectural epoch.

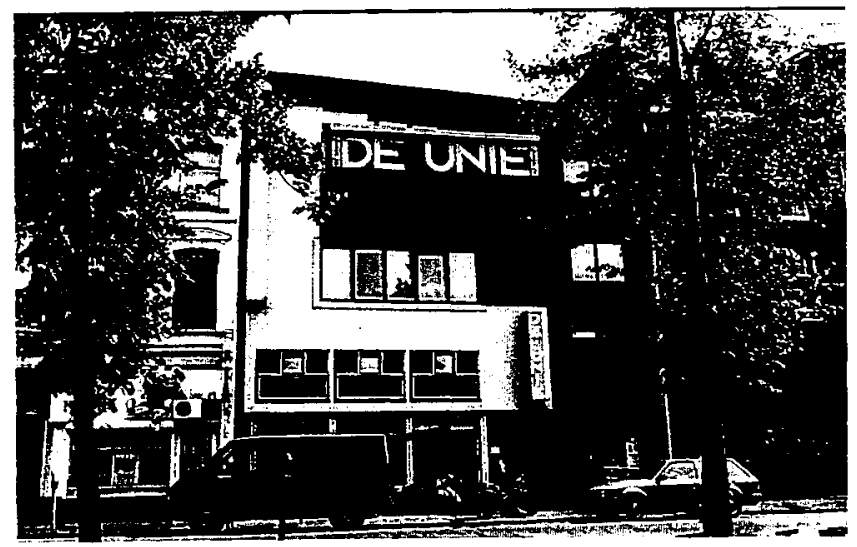

Fig. 3. J.J.P. Oud, Cafe de Unie, demolished in World War II, the facade reconstructed in the $1980 \mathrm{~s}$

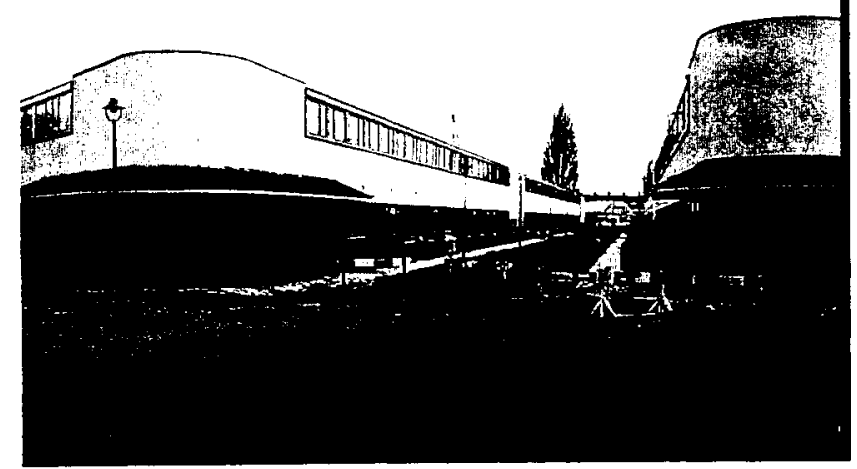

Fig. 2. J.J.P. Oud, Kiefhoek Housing in Rotterdam, total reconstruction by Wietse Patijn in 1993

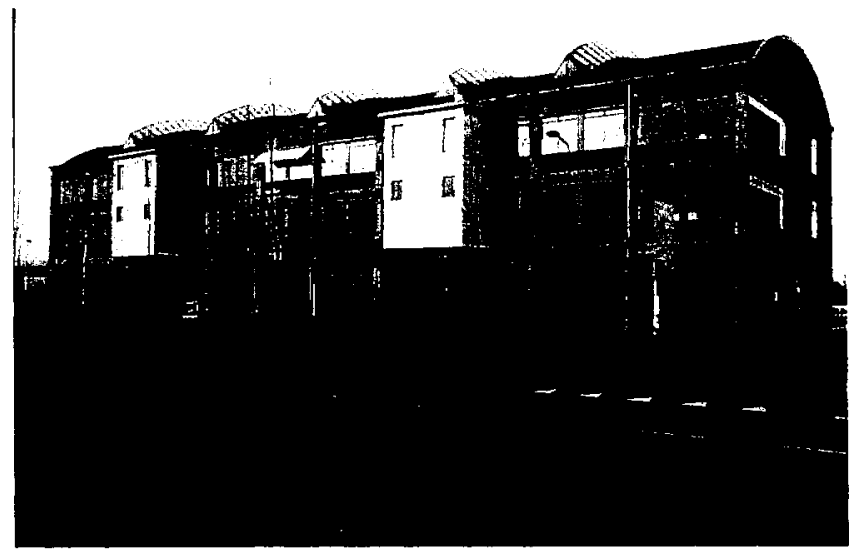

Fig. 5. The Wiebengahal in Maastricht, re-use as an exhibition hall

\section{Existing buildings first demolished and thereafter reconstructed:}

The construction of the buildings was so defective that housing complexes, after several restorations that could not maintain the buildings in the necessary condition, were demolished and reconstucted. A very clear example is the reconstruction of the social housing complex Kiefhoek by Oud in Rotterdam New drawings had to be reconstructed, because the originals were lost during World War II. The whole project (arch. Wijtze Patijn) has been one long decision-making process about choices of building techniques and materials, about how the interior organisation of the houses can be adjusted to the needs of the living of to day and the question of authenticity. The Wiebengahall is situated besides the new Bonnefantenmuseum of Rossi in Maastricht. The building is today the only surviving fragment, earlier part of a much larger factory complex. The building was stripped down to its main construction and thereafter reconstructed with new brickwork and several alterations to be able to function as an additional exhibition space.

\section{Taking a building apart for later rebuilding or} mechanical removal of a building to another site:

Some buildings have lost their function at their original site, or they simply need to be removed. Removal is normally easier for wooden buildings or buildings built in a tectonic system. One of the solutions for the old Airport in Copenhagen by Vilhelm Lauritzen will be to move the building mechanically to another site.

\section{Additions:}

The architectural quality of additions, some of them controversial, depend a lot on the choice of architect. Additions subordinate to the existing building or visually transparent seem to be a possible solution. Others dominate the existing building for example the new extension of the Stadion Feienoord by Brinkman van de Vlugt in Rotterdam or the new highrise on top of Rotterdam's Stock Exchange. 


\section{Subtractions:}

Existing buildings can have inappropriate interiors; new functions often need more space. One solution is to subtract walls and parts of the interiors, in order to create space for new functions.

\section{Natural decay of a building into a ruin:}

The Zonnestraal Sanatorium of architect Duiker is one of many examples of buildings from the Modern Movement in decay. The sanatorium was originally planned to last as long as the problem of tuberculosis existed. There are still discussions, whether or not this complex should be allowed to become a total ruin. A buildings period of ruin has today become an important object for studies and research.

\section{WHICH BUILDING SHOULD BE SAVED AND HOW?}

An authentic and unreplaceable example of Modern Movement architecture should be restored to its original state. If there several similar authentic examples, exist some of them may be chosen and the others saved in a more pragmatic form. Replaceable examples should be well documented for research by future generations.

In the following the buildings are arranged in categories of different type and importance: avant gardistic manifestos, both built and unbuilt. Many times they are connected with experiments in the field of the plastic arts. Examples are the futurist designs of Sant' Elia, the architectural models of Van Eesteren and Van Doesburg in the early 20th Century, Rietveld's Schröder house in Utrecht, the designs of Vladimir Tatlin, Mendelsohn's Einsteinturm in Potsdam, Le Corbusier's Pavilion de l'Esprit Nouveau and the Bauhaus in Dessau.

Despite the fact that they are often distinguished by a fixation on form and space and not by the balance of functional, psychological and formal design decisions, which is so characteristic for the best examples of the Modern Movement, they were of crucial importance as pioneers and propagandists. Every alteration in these buildings will destroy their essence, although several of them only exist as reconstructions today.

In the second place there is a category that is determined to a high degree by typological considerations, and in a somewhat lesser degree by artistic ones. This category includes hospitals, schools, factories, sanatoriums, office buildings etc. In contrast to the built manifestos, they demonstrate in most cases a perfect balance between functional, technical, psychological and formal design decisions.

On one hand, this kind of building naturally requires careful functional analysis of the building program, but on the other hand it provided the opportunity to make the desired modern society and culture visible in everyday life.

These buildings between the utopian manifestos and the housing areas, which reflect the more pragmatic and social needs of the time.

In the third place, there is the broad category of housing and town planning with relatively modest roles for aesthetic values. Here the avantgardistic attitude did not manifest itself in artistic experiments, but in a number of innovations in the field of mass housing and town planning with the ultimate goal of contributing to a better society. Finally it is important to add the special category of the villa. Since the villa has so often been among the strongest examples of architecture in the Modern Movement.

\section{THE IMPORTANCE OF A BUILDING IN A NATIONAL CONTRA AN INTERNATIONAL CONTEXT}

A building of great national importance does not necessarily have a similar international importance or vice verse. The architecture of the Dutch architect Dudok ranges very highly in an international context. His work contains an interesting blend of inspirations from the architecture of F. L. Wright, Art Deco and the Dutch 'Nieuwe Zakelijkheid' ('New Objectivity'). In The Netherlands, his work is considered to be too great a mixture of different influences. This is the reason why his work does not range as high national, as does internationally.

In Denmark, the work of Mogens Lassen is an important national contribution to the architecture of the Modern Movement. But his work is not so famous internationally, because the work of Le Corbusier overshadows the artistic contribution of Lassen from an international point of view.

Frank Lloyd Wright is not considered so important for the Modern Movement in the United States. Here are architects such as Mies van der Rohe, Richard Neutra and Marcel Breuer far more influential. They took the new Modern ideas and developed them further. Wright did have his own methods of working, but his influence was of a great importance in Europe, where his work became an important basis for the Modern Movement.

\section{CONCLUSION}

In general, the question is to separate and eliminate the most special characteristics of the period, both ideologically and architecturally. However, even with a certain set of rules for preservation methods, every building still requires its own individual treatment. The preservation of the buildings of this epoch may not result in an array of dead museum pieces and frozen images without their own life. One has to develop a dynamic preservation method that saves the intrinsic values with regard to the benefit for the society of today and the future.

As the architecture of this epoch is so fragile, there is a need for a new attitude towards the methods of conservation. Like the temples of Japan that can only keep their perfection for a limited time and that need to be rebuilt every twenty years, without loosing their authenticity, buildings of the Modern Movement have to be maintained using the newest building techniques, while respecting the architectural experiments of their time. 
The dynamic conservation management of the built environment, and the approach to authentic living traditions requires an appropriate process. Such traditions are becoming rare in the present-day world, and although they should provide the required knowledge and skills for their continuation, they will also need support in the general planning and management in order to maintain their artistic authenticity. 